\title{
Acute traumatic unilateral cervical C4-C5 facet dislocation in pediatric toddlers
}

\author{
Wongthawat Liawrungrueang ${ }^{*}$ (D), Rattanaporn Chamnan, Weera Chaiyamongkol and Piyawat Bintachitt
}

\begin{abstract}
Background: The present study is to highlight the challenges in managing cervical spine injuries in toddlers (less than 4 years of age) without neurological deficit. Cases of unilateral cervical C4-C5 facet dislocation in toddlers are very rare.

Case presentation: A 3-year-old girl suffered cervical spine injury after a motor vehicle collision with unilateral C4C5 facet dislocation without neurological deficit. Magnetic resonance imaging (MRI) showed no spinal cord injury, Frankel grade E. Initial management was cervical spine protection. Definite treatment and complication were discussed with the patient's parents before closed reduction maneuver with minerva cast was applied under sedation. The patient showed no complication after closed reduction and the cervical spine had aligned well in radiographs. The minerva cast was removed at 8 weeks, at which point neck muscle stretching rehabilitation program started. At one-year follow up, the child was asymptomatic, had full active cervical motion and good function. In radiographs, the cervical spine had normal alignment and was healed.

Conclusions: Unilateral cervical facet dislocation in toddlers is very rare. Closed reduction maneuver and the minerva cast applied were optional in this case. The parents were highly satisfied with the effective treatment and outcome.
\end{abstract}

Keywords: Acute unilateral facet dislocation, Perched facet, Pediatric

\section{Background}

Cervical spinal cord injury without radiographic abnormalities (SCIWORA) is more commonly seen in the pediatric age group than in adults. Incidences have been reported as $13-19 \%$ of spinal injuries in children [1-4]. However, the trauma of C3-C7 lower cervical area is especially seen in adolescence and the advanced childhood period. While lower cervical area trauma ratios are $20-30 \%$ in children under 9 years of age, this rises to $70-75 \%$ in adolescence and advanced childhood. In the study of McGrory et al. [5] Facet dislocations can be unilateral or bilateral. They generally develop in connection to the hyperflexion traumas accompanied by rotation. Patients show symptoms with reticular and/or spinal cord base findings. Compared with unilateral, bilateral facet dislocations are more unstable pathologies [6]. Even though diagnosis can be made by lateral

* Correspondence: mint11871@hotmail.com

Department of Orthopedics, Faculty of Medicine, Prince of Songkla

University, 15 Karnjanavanich Road, Songkhla, Hat Yai 90112, Thailand radiography, computed tomography scan $(\mathrm{CT})$ and magnetic resonance imaging (MRI) are necessary to finalize the diagnosis. In early diagnosis cases, reduction can be ensured by traction. In cases in which reduction is ensured, 2-4 months immobilization must be provided by halo or minerva orthosis. In cases where reduction cannot be ensured, reduction and fusion indication appears with anterior or posterior surgeries [6, 7]. Previously reviewed literature and reports showed unilateral cervical C4-C5 facet dislocation in toddlers is very rare and there are even less reports concerning the treatment process. The purpose of this study was to highlight the challenges in managing cervical spine injuries in toddlers (less than 4 years of age) without neurological deficit. Cases of unilateral cervical $\mathrm{C} 4-\mathrm{C} 5$ facet dislocation in toddlers is very rare. The authors describe the management of an acute pediatric unilateral facet dislocation.

(c) The Author(s). 2020 Open Access This article is distributed under the terms of the Creative Commons Attribution 4.0 International License (http://creativecommons.org/licenses/by/4.0/), which permits unrestricted use, distribution, and reproduction in any medium, provided you give appropriate credit to the original author(s) and the source, provide a link to the Creative Commons license, and indicate if changes were made. The Creative Commons Public Domain Dedication waiver (http://creativecommons.org/publicdomain/zero/1.0/) applies to the data made available in this article, unless otherwise stated. 


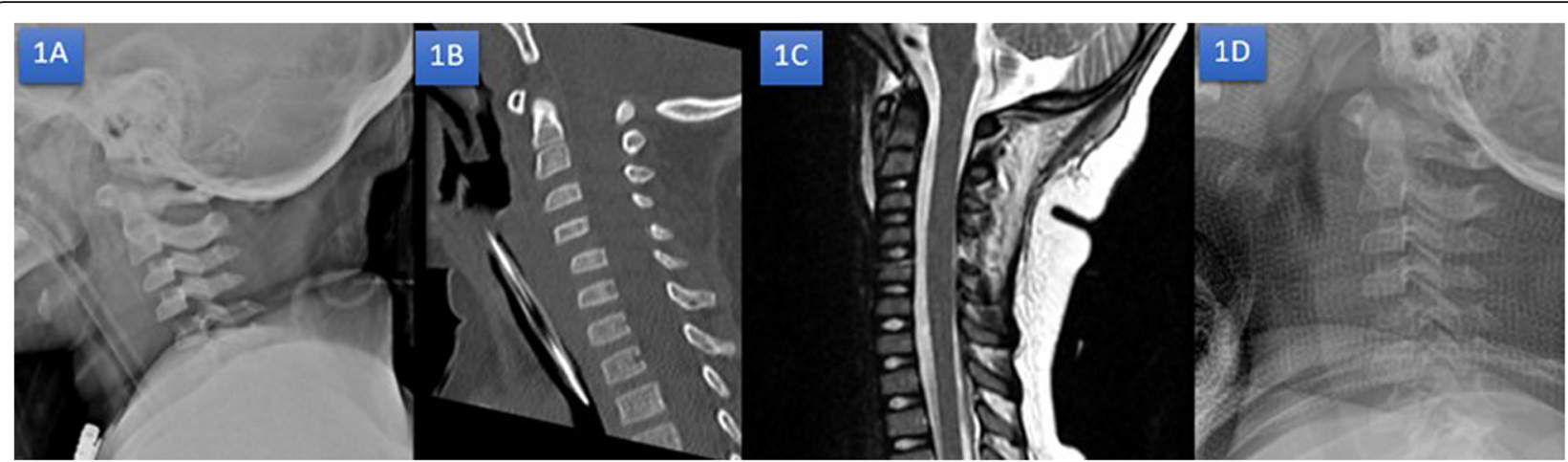

Fig. 1 Radiographs images; Lateral radiograph $x$-ray (1A), sagittal radiograph of $C T$ (1B) and sagittal radiograph of T2 weighted MRI (1C) showed antrolesthesis of C4 on C5 with 25\% translation without spinal cord injury. Repeated lateral radiograph x-ray after closed reduction maneuver with minerva casting (1D)

\section{Case presentation}

A 3-year-old girl suffered cervical spine injury after a motor vehicle collision while sitting in the car without wearing a seatbelt. ATLS protocol was performed on the patient at a local hospital and she was referred to the emergency department at author's hospital within $12 \mathrm{~h}$ of the injury. The pediatric surgeon and our orthopedic team re-evaluated that the status of the patient showed head injury with alteration of consciousness, intubation, cervical spine protection with hard collar and first rib fracture without pneumohemothorax. The emergency radiographs $\mathrm{x}$-ray and $\mathrm{CT}$ brain including cervical spine showed no intracerebral hemorrhage but the cervical spine suffered unilateral cervical C4-C5 facet dislocation. Radiographic features showed anterior dislocation of the affected vertebral body less than the vertebral body in anterior posterior diameter, discordant rotation above and below involved level, facet within intervertebral foramen on oblique view, widening of the disk space and "Bat wing sign" appearance of the overriding facet (Fig. 1a-c).
The patient was taken to the pediatric intensive care unit (PICU) for resuscitation and closed monitoring after hemodynamic was stable. The patient was evaluated by MRI for preoperative planning, and no spinal cord injury was visible. In the next 24 hours, the patient's neurovascular status examination was fully conscious and no neurological deficit (Frankel grade E) then extubation followed. The team discussed with her parents treatment plan and complication. Her parents then denied surgery. The authors applied closed reduction maneuver with minerva cast under sedation. The patient was in Frankel grade E without complication after closed reduction and the cervical spine had good alignment in radiographs (Fig. 1d). The minerva cast was removed at 8 weeks, at which point neck muscle stretching rehabilitation program started. At one-year follow up, the child was asymptomatic, had full active cervical motion and good function. The cervical spine showed normal alignment and had healed in follow up radiographs (Fig. 2). Her parents were highly satisfied with our effective treatment and outcome.

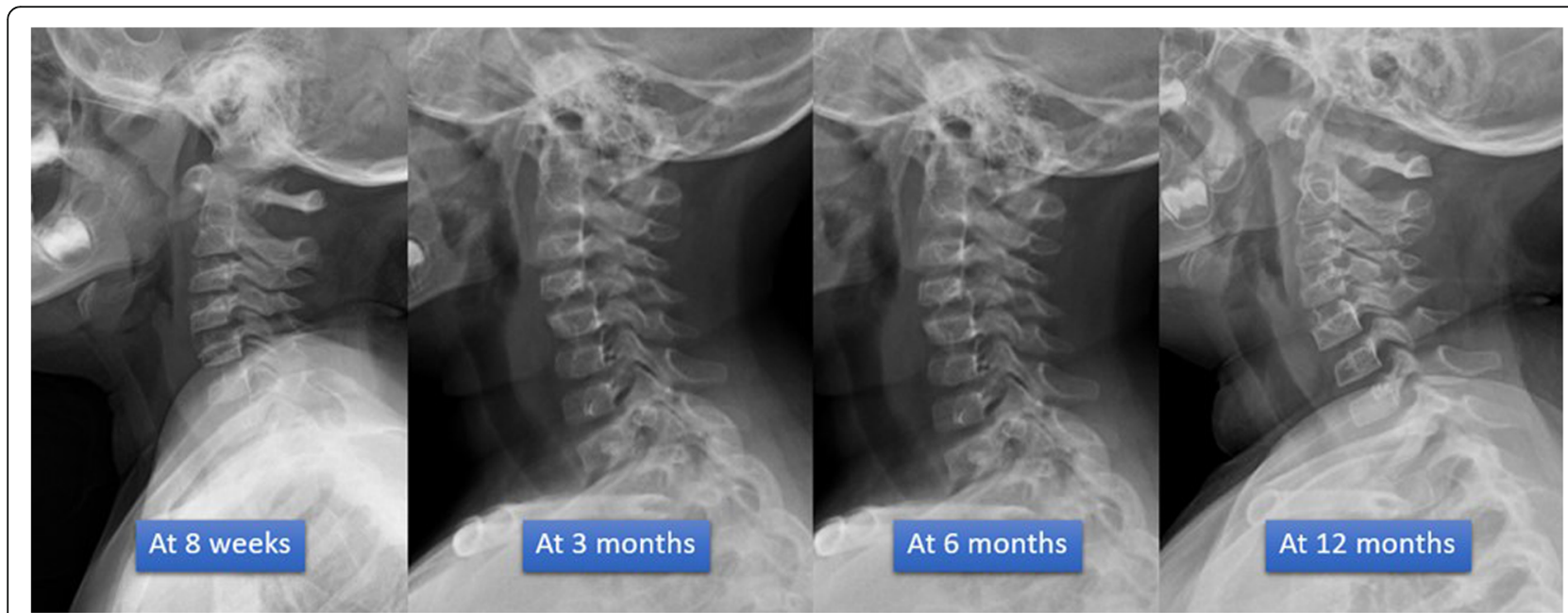

Fig. 2 Radiographs images after removing minerva cast; showing the cervical spine had improved alignment and healed in follow up radiographs 
Table 1 Summary of published reports on the management of traumatic pediatric unilateral cervical dislocation

\begin{tabular}{|c|c|c|c|c|c|c|c|}
\hline Authors \& Year & Sex & $\begin{array}{l}\text { Patient } \\
\text { Age }\end{array}$ & $\begin{array}{l}\text { Level of } \\
\text { injured }\end{array}$ & $\begin{array}{l}\text { Injury } \\
\text { pattern }\end{array}$ & $\begin{array}{l}\text { Neurological } \\
\text { status }\end{array}$ & Definition of Management & Final Outcome \\
\hline $\begin{array}{l}\text { Faschingbauer M, } \\
\text { et al., } 2008[9]\end{array}$ & $\mathrm{F}$ & $12 \mathrm{yrs}$ & C6-7 & $\begin{array}{l}\text { Traffic } \\
\text { accident }\end{array}$ & $\begin{array}{l}\text { No neurological } \\
\text { deficit }\end{array}$ & $\begin{array}{l}\text { C6-7 anterior fusion and stabilization, and C5-7 } \\
\text { posterior spinous process cerclage wire and fusion }\end{array}$ & $\begin{array}{l}\text { Complete } \\
\text { recovery }\end{array}$ \\
\hline $\begin{array}{l}\text { Parada SA, et al., } \\
2010[10]\end{array}$ & M & $9 y r s$. & C4-5 & Wrestling & $\begin{array}{l}\text { No neurological } \\
\text { deficit }\end{array}$ & $\begin{array}{l}\text { Manual reduction and stabilization with cervical } \\
\text { collar }\end{array}$ & $\begin{array}{l}\text { Complete } \\
\text { recovery }\end{array}$ \\
\hline $\begin{array}{l}\text { Sellin JN, et al., } \\
2014 \text { [6] }\end{array}$ & $\mathrm{F}$ & 7 yrs. & C3-4 & $\begin{array}{l}\text { Fall from } \\
\text { height }\end{array}$ & $\begin{array}{l}\text { No neurological } \\
\text { deficit }\end{array}$ & $\begin{array}{l}\text { C2-4 posterior cervical fusion, stabilized with lateral } \\
\text { mass screws \& rod }\end{array}$ & $\begin{array}{l}\text { Complete } \\
\text { recovery }\end{array}$ \\
\hline $\begin{array}{l}\text { Qu W, et al., } \\
2016[11]\end{array}$ & M & 5 yrs. & C3-4 & $\begin{array}{l}\text { Traffic } \\
\text { accident }\end{array}$ & $\begin{array}{l}\text { No neurological } \\
\text { deficit }\end{array}$ & C3-4 posterior cervical fusion stabilized & $\begin{array}{l}\text { Complete } \\
\text { recovery }\end{array}$ \\
\hline
\end{tabular}

\section{Discussion and conclusions}

The study subjects is a traumatic pediatric unilateral cervical facet dislocation in toddler (18 months -3 yrs.) which is a very rare condition. The most common causes of pediatric subaxial servical spine injury are motor vehicle accidents (50\%) and sports-related activities (25\%) [8]. Previously reviewed literature and case reports showed very rare pediatric subaxial cervical unilateral facet dislocation (Table 1).

Knowledge of the anatomical characteristics of pediatric unilateral cervical facet dislocation is very important. Three studies $[6,9,10]$ reported three cases of pediatric unilateral cervical facet dislocation without neurological deficit. All reports were performed surgical treatment in school-aged children (512 yrs.) and reported a successful clinical outcome. Only one report, Parada et al., 2010 [11] reported a successful clinical outcome by conservative treatment with manual reduction and stabilization with cervical collar.

In our case, the purpose was to highlight the challenges in managing cervical spine injuries in toddlers without neurological deficit. The authors described the management of an acute pediatric unilateral facet dislocation by manual reduction and stabilization with minerva cast. The patient was asymptomatic, had full active cervical motion and good function. The cervical spine showed normal alignment and had healed in radiographs at one-year follow up. Unilateral cervical facet dislocation without neurological deficit in toddlers is very rare. The closed reduction maneuver and applied minerva cast is optional for treatment if successful manual reduction and stabilization with cervical orthosis has a good clinical outcome.

\section{Abbreviations \\ $\mathrm{CT}$ : Computed tomography scan; MRI: Magnetic resonance imaging; PICU: Pediatric intensive care unit; SCIWORA: Spinal cord injury without radiographic abnormalities}

\section{Acknowledgements}

The authors would like to thank Geoffrey Alan Cox for proofreading the English of this report.

\section{Authors' contributions}

Study concept and design by WL, RC, WC, and PB. Participation in the initial management, treatment performed and follow-up by PB. Analysis and interpretation of data and review of the literature by WL. Drafting of the manuscript and critical revision of the manuscript for important intellectual content by WL. All authors read and approved the final version of the manuscript.

\section{Funding}

Not applicable.

\section{Availability of data and materials}

Data sharing is not applicable to this case report as no datasets were generated or analyzed during the current study.

\section{Ethics approval and consent to participate}

The patient provided written informed consent to have the case details and any accompanying images published. Prince of Songkla University Institutional Review Board, Faculty of Medicine, Songklanagarind Hospital, Prince of Songkla University. (IRB number EC 62-369-11-4) provided their approval to publish the case details. The patient's parents had the opportunity to refuse. The parents requested that the patient's personal information remained confidential. There was no cost or harm to the patient as a result of the study.

\section{Consent for publication}

Written informed consent was obtained from the patient's parent for publication of this case report, including any accompanying images. A copy of the consent is available for review by the Editor of this journal.

\section{Competing interests}

The authors declare that they have no competing interests.

Received: 20 October 2019 Accepted: 23 December 2019

Published online: 03 January 2020

\section{References}

1. Hamilton MG, Myles ST. Pediatric spinal injury: review of 174 hospital admissions. J Neurosurg. 1992;77(5):700-4.

2. Osenbach RK, Menezes AH. Pediatric spinal cord and vertebral column injury. Neurosurgery. 1992;30(3):385-90.

3. Martinez-Perez R, Munarriz PM, Paredes I, Cotrina J, Lagares A. Cervical spinal cord injury without computed tomography evidence of trauma in adults: magnetic resonance imaging prognostic factors. World Neurosurg. 2017:99:192-9.

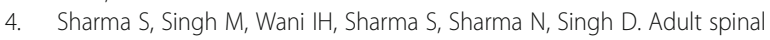
cord injury without radiographic abnormalities (SCIWORA): clinical and radiological correlations. J Clin Med Res. 2009;1(3):165-72.

5. McGrory BJ, Klassen RA, Chao EY, Staeheli JW, Weaver AL. Acute fractures and dislocations of the cervical spine in children and adolescents. J Bone Joint Surg Am. 1993;75(7):988-95.

6. Sellin JN, Shaikh K, Ryan SL, Brayton A, Fulkerson DH, Jea A. Clinical outcomes of the surgical treatment of isolated unilateral facet fractures, subluxations, and dislocations in the pediatric cervical spine: report of eight cases and review of the literature. Childs Nerv Syst. 2014;30(7):1233-42. 
7. Knox JB, Schneider JE, Cage JM, Wimberly RL, Riccio Al. Spine trauma in very young children: a retrospective study of 206 patients presenting to a level 1 pediatric trauma center. J Pediatr Orthop. 2014;34(7):698-702.

8. Dogan S, Safavi-Abbasi S, Theodore N, Horn E, Rekate HL, Sonntag VK. Pediatric subaxial cervical spine injuries: origins, management, and outcome in 51 patients. Neurosurg Focus. 2006;20(2):E1.

9. Faschingbauer M, Schulz AP, Seide K, Jürgens C. Unstable cervical spinal injury in children - case report and review of the literature. Eur I Trauma Emerg Surg. 2008;34(5):515-21.

10. Parada SA, Arrington ED, Kowalski KL, Molinari RW. Unilateral cervical facet dislocation in a 9-year-old boy. Orthopedics. 2010;33(12):929.

11. Qu W, Hao D, Wu Q, Song Z, Liu J. Surgical treatment for irreducible pediatric subaxial cervical unilateral facet dislocation: case report. J Neurosurg Pediatr. 2016;17(5):607-11.

\section{Publisher's Note}

Springer Nature remains neutral with regard to jurisdictional claims in published maps and institutional affiliations.

Ready to submit your research? Choose BMC and benefit from:

- fast, convenient online submission

- thorough peer review by experienced researchers in your field

- rapid publication on acceptance

- support for research data, including large and complex data types

- gold Open Access which fosters wider collaboration and increased citations

- maximum visibility for your research: over $100 \mathrm{M}$ website views per year

At BMC, research is always in progress.

Learn more biomedcentral.com/submissions 